\title{
Incidence rates and trends of lip, oral and oro-pharyngeal cancers in Portugal
}

\author{
Luís S. Monteiro', Luís Antunes ${ }^{2}$, Maria J. Bento ${ }^{2}$, Saman Warnakulasuriya ${ }^{3}$ \\ ${ }^{1}$ Department of Medicine and Oral Surgery, Dental Sciences Group - Health Sciences Research Centre, Instituto Superior de Ciências da \\ Saúde Norte Paredes, Portugal; ${ }^{2}$ Department of Epidemiology, Portuguese Institute of Oncology (IPO Porto), Porto, Portugal; ${ }^{3}$ Oral \\ Medicine, Department of Clinical \& Diagnostic Sciences, King's College London Dental Institute WHO, Collaborating Centre for Oral \\ Cancer, London, UK
}

OBJECTIVES: To analyse the trends and patterns of lip, oral and oro-pharyngeal cancer incidence in Portugal between 1998 and 2007.

PATIENTS AND METHODS: Data on lip, oral and oro-pharyngeal cancers was collected from the databases maintained at the three main Regional Cancer Registries of Portugal (1998-2007). The data were analysed by gender, age and by site. Incidence rates were age standardized by the direct method, and joinpoint regression was used to estimate trends in incidence.

RESULTS: During this 10-year period, a total of 9623 cases of lip, oral and oropharynx cancers were reported, 7565 (78.6\%) in males and 2058 (21.4\%) in females. There was an increase in the age-standardized incidence of oral cancers by $1.96 \%$ per year for both sexes grouped together and an increase of $4.34 \%$ per year for the female group. Oro-pharyngeal cancer showed an increase incidence trend of $3.49 \%$ per year for both sexes grouped together and an increase of $3.49 \%$ per year for male group among the sites analysed. Lip cancer showed a decrease in its incidence rate.

CONCLUSION: In view of rising trends, it is necessary to implement policies on oral cancer control by initiating campaigns on oral cancer awareness and screening and to harness political measures on tobacco and alcohol control for the Portuguese population.

J Oral Pathol Med (2013) 42: 345-35I

Keywords: incidence; lip cancer; oral cancer; oro-pharyngeal cancer; Portugal; trends

Correspondence: Luís Silva Monteiro, PhD, MSc, DDS, Department of Medicine and Oral Surgery, Centro de Investigação em Ciências da Saúde (CICS), Instituto Superior de Ciências da Saúde - Norte, Rua Central de Gandra, 1317, 4585-116 Gandra PRD, Portugal. Tel: +351919120226, Fax: +351224157102, E-mail: lmonteiro_md@hotmail. com

Accepted for publication August 28, 2012

\section{Introduction}

Oral and pharyngeal cancers are a major public health problem worldwide (1). The most recent estimated incidence of oral and pharyngeal cancer (excluding nasopharynx) in the world is around 399600 new cases in 2008, being the sixth most common cancer (2). However, the incidence of this cancer varies worldwide (approximately 20-fold) reflecting variations in the prevalence of specific risk factors within the regions (3). The areas characterized by high incidence rates for oral and oro-pharyngeal cancer are found in the Pacific regions (e.g. Papua New Guinea and other pacific islands in Melanesia), South and Southeast of Asia (e.g. Taiwan, Maldives, Bangladesh, Sri Lanka, Pakistan, Brunei and India), some parts of Europe (e.g. Hungary, Luxembourg, Slovakia, France and particularly lip cancer in Spain), and parts of Latin America and the Caribbean (e.g. Puerto Rico, Cuba, Brazil, Dominican Republic and Uruguay (2). In some high-risk countries such as Sri Lanka, India, Pakistan and Bangladesh, oral cancer is the most common cancer in men and may contribute up to $25 \%$ of all new cases of cancer (1). Smoking, alcohol use, smokeless tobacco products and human papillomavirus (HPV) infection are the major risk factors, with an attributable risk of $80 \%$ for both tobacco and alcohol (4).

In Portugal, the estimated incidence of oral and pharyngeal cancer for 2008 (excluding nasopharynx) was 1468 new cases, being the sixth most common cancer in males with 1194 new cases and the sixteenth in females with 274 new cases per year (2).

Variations in the trends of occurrence of oral and pharyngeal cancers have been reported internationally. In some industrialized countries (e.g. Denmark, Netherlands, Japan, England and Scotland), a rising incidence has been observed in the last decades, while there has been a decline in other countries such as Sri Lanka, Thailand or Spain (5-7). In Portugal, a detailed comparative analysis of trends in oral and oropharyngeal cancer has not been performed.

The aim of the present work is to analyse the trends and patterns of lip, oral cavity and oro-pharyngeal cancer incidence in Portugal between 1998 and 2007. 
346

\section{Material and methods}

Information was collected from the databases maintained at the three main Regional Cancer Registries of Portugal (RORENO, ROR-Centro and ROR-Sul). All new malignant lip, oral cavity and oropharynx malignant neoplasms, diagnosed between 1 January 1998 and 31 December 2007, occurring in men and women of any age, resident in mainland Portugal or Madeira archipelago, were considered for our analysis. During the study period (1998-2007), two different revisions of the International Classification of the Diseases (ICD) were used. As differences between the two classifications were minor, we recoded all cases according to the 10th revision of the ICD (8). The cancers considered in this study were lip (CO0), oral cavity, which includes tongue (C01 and $\mathrm{C} 02$ ), gum (C03), floor of the mouth (C04), palate and other unspecified parts of the mouth (C05 and C06). Cancers of tonsils and oropharynx and other illdefined sites and pharynx were grouped in oropharynx cancers (C09, C10 and C14). Malignant neoplasms of salivary glands (C07-08), nasopharynx and hypopharynx (C11-13) were not considered in this analysis.

The incidence rates were age standardized to the European Standard Population by the direct method and standard errors obtained according to the method described by Boyle and Parkin (9). Joinpoint regression was used to estimate trends in incidence and possibly detect inflexion points (10).

\section{Results}

A total of 9623 cases of lip, oral and oropharynx cancers were reported between 1998 and 2007, 7565 (78.6\%) in males and $2058(21.4 \%)$ in females, with a M:F ratio of 3.7:1. Squamous cell carcinomas were the most frequent histological type reported $(87.1 \%)$.

A difference in number and crude incidence rates between sex distribution for all lip, oral cavity and oropharyngeal cancers is clearly observed (Table 1) being 3-4 times higher in males than females. This ratio is maintained over the group of cancers studied, being higher in oropharyngeal cancers (5-13 times higher in men) and slightly lower in lip cancers (2-3 times higher in men; Table 1).

Lip, oral cavity and oro-pharyngeal cancers were more common in adults over 45 years of age (Table 2) representing $89.2 \%$ of all tumours in 2007 . The highest incidence was observed in the age group above 75 years of age for both sexes together and the female group individually, although in males the age group of 60-64 years was the most affected (Fig. 1).

The specific location with highest incidence out of all oral sites was the tongue (Fig. 2). Oro-pharyngeal cancer was the second leading cancer out of all cancers studied. Lip cancer had the second highest incidence in the initial year of the study but in 2007 occupies the fourth position after palate, and unspecified sites (C05 and C06).

When lip, oral cavity and oro-pharyngeal cancers were considered together the trend analysis of age-standardized incidence rates using joinpoint regression showed an increasing trend since 2005 for both sexes grouped together (11.19\% per year since 2005; $P<0.05$; Fig. 3 ). The highest reported incidence was in 2007 (9.62/100 000) and the lowest in 1999 (7.6/100 000). This trend was also displayed in the female group with an increase of $7.58 \%$ per year since $2003(P<0.05)$.

For the oral cavity cancers (C01-C06), there was an increase in the age-standardized incidence of $1.96 \%$ per year over the period studied for both sexes grouped together $(P<0.05)$. The highest reported incidence was in 2007 (age-standardized rate 5.49/100 000) and the lowest in 1999 (3.96/100 000; Fig. 3). The female group showed a significant increase of $4.34 \%$ per year $(P<0.05)$. There was a slight increase of this cancer in men $(1.30 \%$ per year) but without statistical significance.

The oro-pharyngeal cancer group (C09, C10 and C14) showed a rising trend of $3.49 \%$ per year for its incidence in both sexes grouped together $(P<0.05)$ with the highest reported incidence being in $2007(2.79 / 100$ 000) and the lowest in 2000 (1.88/100 000; Fig. 3). This increase was significant and higher in men $(3.49 \%$ per year; $P<0.05)$. There was an increase of this cancer in the female group (2.02\% per year) but without statistical significance.

The incidence of lip cancer (CO0) showed a significant decline until 2005 for both sexes with the highest reported incidence being in $1998(1.87 / 100000)$ and the lowest in 2005 (0.95/100 000; Fig. 3). A reduction of $7.68 \%$ per year was noted until $2005(P<0.05)$. This reduction was observed in the male group $(-8.64 \%$ per year until 2005 , $P<0.05)$ as well as in the female group $(-3.49 \%$ per year, $P<0.05)$.

\section{Discussion}

We observed a significant increase in the incidence of oral and oro-pharyngeal cancers over a 10-year period (19982007) for both sexes in Portugal. The highest incidence was recorded in 2007 reflecting first a stable and then a rising trend for this cancer in Portugal since 1998. This may be related to the high tobacco and alcohol consumption in the last decades in Portugal. Rising incidence of oral cancer in Europe was first reported from Denmark in late 1980 and then from Scotland $(11,12)$. For England and Scotland, such rises were also confirmed following a 10-year study (13). Many European countries subsequently reported rising trends until the end of the last century (14). Nevertheless, more recently a decrease in oral and pharyngeal cancer incidence in some European countries in males has been reported. Karim-Kos et al. (7) observed an estimated decrease in oral and pharyngeal cancer combined among males in Ireland, France, Switzerland, Italy, Spain and Slovenia. For females, our data are in line with the rising trends observed in most of European countries including Northern Europe (England, Scoland and Demark), France and the Netherlands $(7,15)$.

Based on our analysis, oral cancer incidence has increased in both sexes (1.96\%/year) especially in the female group (4.3\%/year). Braakhuis et al. (16) observed an increase of oral cancer of $0.5 \%$ and $2.0 \%$ per year for males and females, respectively, in the Netherlands. Moreover, some countries that reported a decrease of oral cancer in males, showed an increase in the incidence among females. Ligier et al. (17) reported a significant increase in the incidence of oral cancer in French females and a decrease in 
Table 1 Incidence of lip, oral and oro-pharyngeal cancers in Portugal (1998-2007) by sex distribution

\begin{tabular}{|c|c|c|c|c|c|c|c|c|c|c|}
\hline & 1998 & 1999 & 2000 & 2001 & 2002 & 2003 & 2004 & 2005 & 2006 & 2007 \\
\hline \multicolumn{11}{|c|}{ All sites $(\mathrm{C} 00, \mathrm{C} 01-06, \mathrm{C} 09-10, \mathrm{C} 14)$} \\
\hline \multicolumn{11}{|c|}{ All } \\
\hline$n$ & 913 & 860 & 896 & 935 & 925 & 919 & 942 & 980 & 1053 & 1200 \\
\hline $\mathrm{CR}$ & 9.21 & 8.62 & 8.94 & 9.25 & 9.09 & 8.97 & 9.15 & 9.48 & 10.16 & 11.56 \\
\hline ASR & 8.21 & 7.60 & 7.89 & 8.05 & 7.79 & 7.61 & 7.72 & 7.92 & 8.49 & 9.62 \\
\hline \multicolumn{11}{|l|}{ Males } \\
\hline$n$ & 724 & 666 & 716 & 752 & 738 & 728 & 744 & 752 & 796 & 949 \\
\hline CR & 15.16 & 13.86 & 14.81 & 15.41 & 15.02 & 14.71 & 14.95 & 15.05 & 15.89 & 18.91 \\
\hline ASR & 14.58 & 13.21 & 14.01 & 14.41 & 13.83 & 13.45 & 13.58 & 13.62 & 14.31 & 16.87 \\
\hline \multicolumn{11}{|l|}{ Females } \\
\hline$n$ & 189 & 194 & 180 & 183 & 187 & 191 & 198 & 228 & 257 & 251 \\
\hline CR & 3.68 & 3.76 & 3.47 & 3.50 & 3.56 & 3.61 & 3.73 & 4.28 & 4.81 & 4.69 \\
\hline ASR & 2.76 & 2.74 & 2.62 & 2.52 & 2.57 & 2.54 & 2.62 & 2.87 & 3.31 & 3.22 \\
\hline \multicolumn{11}{|l|}{ Lip (C00) } \\
\hline \multicolumn{11}{|l|}{ All } \\
\hline$n$ & 230 & 197 & 166 & 162 & 190 & 156 & 147 & 138 & 194 & 200 \\
\hline CR & 2.32 & 1.98 & 1.66 & 1.60 & 1.87 & 1.52 & 1.43 & 1.34 & 1.87 & 1.93 \\
\hline ASR & 1.87 & 1.55 & 1.30 & 1.26 & 1.41 & 1.10 & 1.04 & 0.95 & 1.33 & 1.35 \\
\hline \multicolumn{11}{|l|}{ Males } \\
\hline$n$ & 163 & 146 & 119 & 116 & 134 & 113 & 102 & 85 & 133 & 146 \\
\hline $\mathrm{CR}$ & 3.41 & 3.04 & 2.46 & 2.38 & 2.73 & 2.28 & 2.05 & 1.70 & 2.65 & 2.91 \\
\hline \multirow{2}{*}{\multicolumn{11}{|c|}{ Females }} \\
\hline & & & & & & & & & & \\
\hline$n$ & 67 & 51 & 47 & 46 & 56 & 43 & 45 & 53 & 61 & 54 \\
\hline CR & 1.30 & 0.99 & 0.91 & 0.88 & 1.07 & 0.81 & 0.85 & 0.99 & 1.14 & 1.01 \\
\hline ASR & 0.88 & 0.65 & 0.61 & 0.58 & 0.69 & 0.49 & 0.54 & 0.54 & 0.62 & 0.56 \\
\hline \multicolumn{11}{|c|}{ Oral Cavity (C01-C06) } \\
\hline \multicolumn{11}{|c|}{ All } \\
\hline$n$ & 467 & 441 & 526 & 558 & 510 & 511 & 541 & 555 & 585 & 673 \\
\hline $\mathrm{CR}$ & 4.71 & 4.42 & 5.25 & 5.52 & 5.02 & 4.99 & 5.26 & 5.37 & 5.65 & 6.49 \\
\hline ASR & 4.29 & 3.96 & 4.72 & 4.85 & 4.35 & 4.26 & 4.50 & 4.51 & 4.80 & 5.49 \\
\hline \multicolumn{11}{|l|}{ Males } \\
\hline$n$ & 380 & 329 & 412 & 446 & 411 & 383 & 429 & 422 & 423 & 517 \\
\hline $\mathrm{CR}$ & 7.96 & 6.85 & 8.52 & 9.14 & 8.37 & 7.74 & 8.62 & 8.45 & 8.44 & 10.30 \\
\hline ASR & 7.73 & 6.63 & 8.14 & 8.58 & 7.76 & 7.10 & 7.90 & 7.65 & 7.67 & 9.30 \\
\hline \multicolumn{11}{|l|}{ Females } \\
\hline$n$ & 87 & 112 & 114 & 112 & 99 & 128 & 112 & 133 & 162 & 156 \\
\hline $\mathrm{CR}$ & 1.69 & 2.17 & 2.20 & 2.14 & 1.88 & 2.42 & 2.11 & 2.49 & 3.03 & 2.91 \\
\hline ASR & 1.30 & 1.60 & 1.70 & 1.58 & 1.36 & 1.77 & 1.51 & 1.73 & 2.23 & 2.07 \\
\hline \multicolumn{11}{|c|}{ Oropharynx (C09-C10, C14) } \\
\hline \multicolumn{11}{|c|}{ All } \\
\hline$n$ & 216 & 222 & 204 & 215 & 225 & 252 & 254 & 287 & 274 & 327 \\
\hline $\mathrm{CR}$ & 2.18 & 2.23 & 2.04 & 2.13 & 2.21 & 2.46 & 2.47 & 2.78 & 2.65 & 3.15 \\
\hline ASR & 2.05 & 2.09 & 1.88 & 1.95 & 2.04 & 2.26 & 2.19 & 2.47 & 2.36 & 2.79 \\
\hline \multicolumn{11}{|l|}{ Males } \\
\hline$n$ & 181 & 191 & 185 & 190 & 193 & 232 & 213 & 245 & 240 & 286 \\
\hline $\mathrm{CR}$ & 3.79 & 3.98 & 3.83 & 3.89 & 3.93 & 4.69 & 4.28 & 4.90 & 4.79 & 5.70 \\
\hline ASR & 3.76 & 3.91 & 3.71 & 3.74 & 3.77 & 4.48 & 4.01 & 4.55 & 4.47 & 5.25 \\
\hline \multicolumn{11}{|l|}{ Females } \\
\hline$n$ & 35 & 31 & 19 & 25 & 32 & 20 & 41 & 42 & 34 & 41 \\
\hline CR & 0.68 & 0.60 & 0.37 & 0.48 & 0.61 & 0.38 & 0.77 & 0.79 & 0.64 & 0.77 \\
\hline ASR & 0.58 & 0.48 & 0.31 & 0.36 & 0.51 & 0.29 & 0.57 & 0.60 & 0.46 & 0.59 \\
\hline
\end{tabular}

$\mathrm{CR}$, crude rate; ASR, age-standardized rate per 100000 population.

males. These results may be related with the different patterns of tobacco and alcohol habits in the last decades among men and women. Although there has been a decline in tobacco consumption across Europe during last decades, in women this habit has declined at a slower rate (16). On the other hand, alcohol plays an important aetiological role in this cancer. Although the alcohol consumption has declined since the beginning of the last century, in 2005 Portugal was ranked the fourth country in the world with the highest consumption of wine per capita (18). The use of beer and distilled drinks has increased particularly in women. The role of binge drinking, which has recently augmented in Portugal, remains to be explored (19). Other risk factors including socio-economic deprivation, and low daily intake of fruit and vegetables may also contribute to oral cancer increases $(3,20,21)$. However, it is difficult to relate these with the present data in Portugal.

The results of many studies from around the world suggest that the incidence of oral cancer is rising in young people $(13,15,22)$. Llewellyn et al. (22) first suggest that factors other than tobacco and alcohol may also be implicated in the development of oral cancer in a proportion 
Table 2 Evolution of the number of cases and crude incidence rate by age for both sexes between 1998 and 2007

\begin{tabular}{|c|c|c|c|c|c|c|c|c|c|c|}
\hline Cancer site & 1998 & 1999 & 2000 & 2001 & 2002 & 2003 & 2004 & 2005 & 2006 & 2007 \\
\hline \multicolumn{11}{|c|}{ All sites $(\mathrm{C} 00, \mathrm{C} 01-\mathrm{C} 06, \mathrm{C} 09-\mathrm{C} 10, \mathrm{C} 14)$} \\
\hline \multicolumn{11}{|c|}{ Aged below 45} \\
\hline$n$ & 95 & 110 & 87 & 121 & 115 & 103 & 104 & 120 & 117 & 117 \\
\hline CR & 1.57 & 1.83 & 1.45 & 2.01 & 1.91 & 1.71 & 1.73 & 2.00 & 1.96 & 1.98 \\
\hline \multicolumn{11}{|c|}{ Aged above 45} \\
\hline$n$ & 818 & 750 & 809 & 814 & 810 & 816 & 838 & 860 & 936 & 1083 \\
\hline CR & 21.08 & 18.98 & 20.21 & 19.92 & 19.51 & 19.38 & 19.61 & 19.83 & 21.29 & 24.32 \\
\hline \multicolumn{11}{|c|}{ Lip (C00) } \\
\hline \multicolumn{11}{|c|}{ Aged below 45} \\
\hline$n$ & 14 & 15 & 4 & 10 & 13 & 6 & 13 & 11 & 11 & 6 \\
\hline $\mathrm{CR}$ & 0.23 & 0.25 & 0.07 & 0.17 & 0.22 & 0.10 & 0.22 & 0.18 & 0.18 & 0.10 \\
\hline \multicolumn{11}{|c|}{ Aged above 45} \\
\hline$n$ & 212 & 180 & 161 & 152 & 176 & 150 & 131 & 126 & 183 & 194 \\
\hline $\mathrm{CR}$ & 5.46 & 4.56 & 4.02 & 3.72 & 4.24 & 3.56 & 3.06 & 2.90 & 4.16 & 4.36 \\
\hline \multicolumn{11}{|c|}{ Oral Cavity (CO1-C06) } \\
\hline \multicolumn{11}{|c|}{ Aged below 45} \\
\hline$n$ & 61 & 58 & 66 & 87 & 76 & 67 & 63 & 67 & 75 & 70 \\
\hline CR & 1.01 & 0.96 & 1.10 & 1.44 & 1.26 & 1.11 & 1.05 & 1.12 & 1.26 & 1.18 \\
\hline \multicolumn{11}{|c|}{ Aged above 45} \\
\hline$n$ & 406 & 381 & 459 & 470 & 433 & 441 & 476 & 487 & 507 & 602 \\
\hline $\mathrm{CR}$ & 10.46 & 9.64 & 11.47 & 11.50 & 10.43 & 10.47 & 11.14 & 11.23 & 11.53 & 13.52 \\
\hline \multicolumn{11}{|c|}{ Oropharynx (C09-C10, C14) } \\
\hline \multicolumn{11}{|c|}{ Aged below 45} \\
\hline$n$ & 20 & 37 & 17 & 24 & 26 & 30 & 28 & 42 & 31 & 41 \\
\hline $\mathrm{CR}$ & 0.33 & 0.62 & 0.28 & 0.40 & 0.43 & 0.50 & 0.47 & 0.7 & 0.52 & 0.69 \\
\hline \multicolumn{11}{|c|}{ Aged above 45} \\
\hline$n$ & 196 & 185 & 187 & 191 & 199 & 222 & 226 & 245 & 243 & 286 \\
\hline CR & 5.05 & 4.68 & 4.67 & 4.67 & 4.79 & 5.27 & 5.29 & 5.65 & 5.53 & 6.42 \\
\hline
\end{tabular}

CR, crude rate per 100000 population.

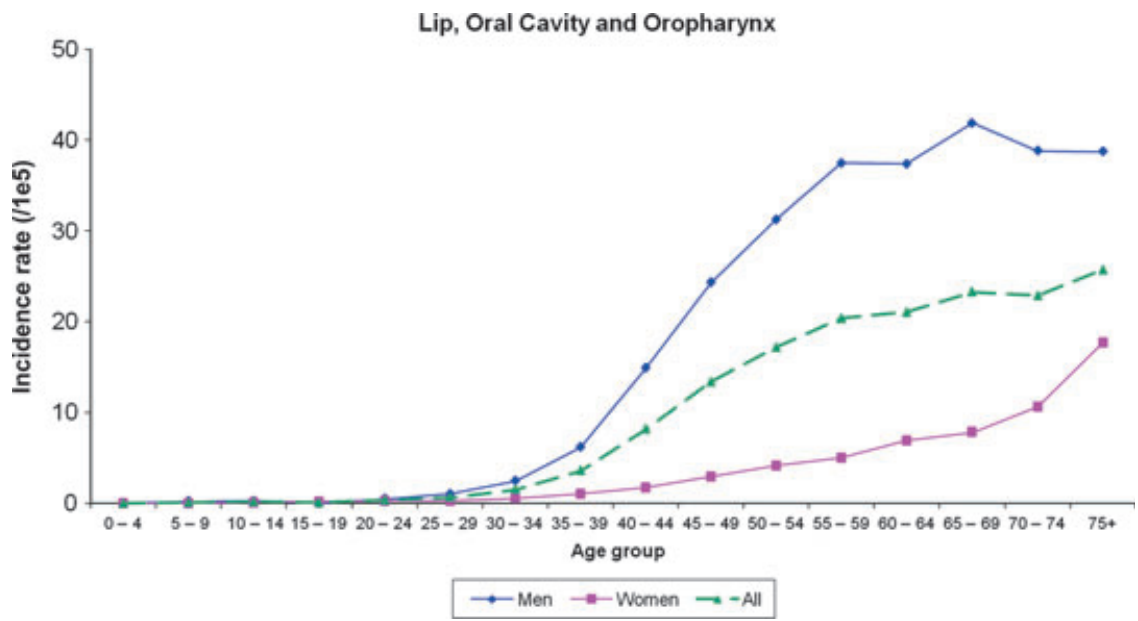

Figure 1 Age-specific incidence rate of lip, oral and oro-pharyngeal cancers over the period from 1998-2007 by gender distribution.

of these younger patients. It has been suggested that HPV is related with the younger presentation of oral cancer (23). However, after the oral mucosa is infected by high-risk HPV, it may take more than 20 years for malignant transformation to develop. In the present work, an increase in oral cancer among the young was not clearly evident or different from that occurred in the older population. Nevertheless, the percentage of oral and oro-pharyngeal cancer in patients under 45 years of age $(10.8 \%)$ is higher in the present data than the $6 \%$ observed in many cancer registries reported in the literature (22).
The most significant trend in the present study was noted in the oro-pharyngeal cancer especially in men. The rising trend of this cancer has been noted in recent decades in European countries including Scotland especially in men (24), Netherlands (16), Denmark (25), and other countries such as United Sates especially in white men (26) and, in the British Columbia especially in men (27). This is currently the fastest growing cancer in Scotland. Many reports attributed this trend to HPV as the cause of this rising incidence (27-29). Sexual behaviour and changing sexual habits in the last decades may be related with 


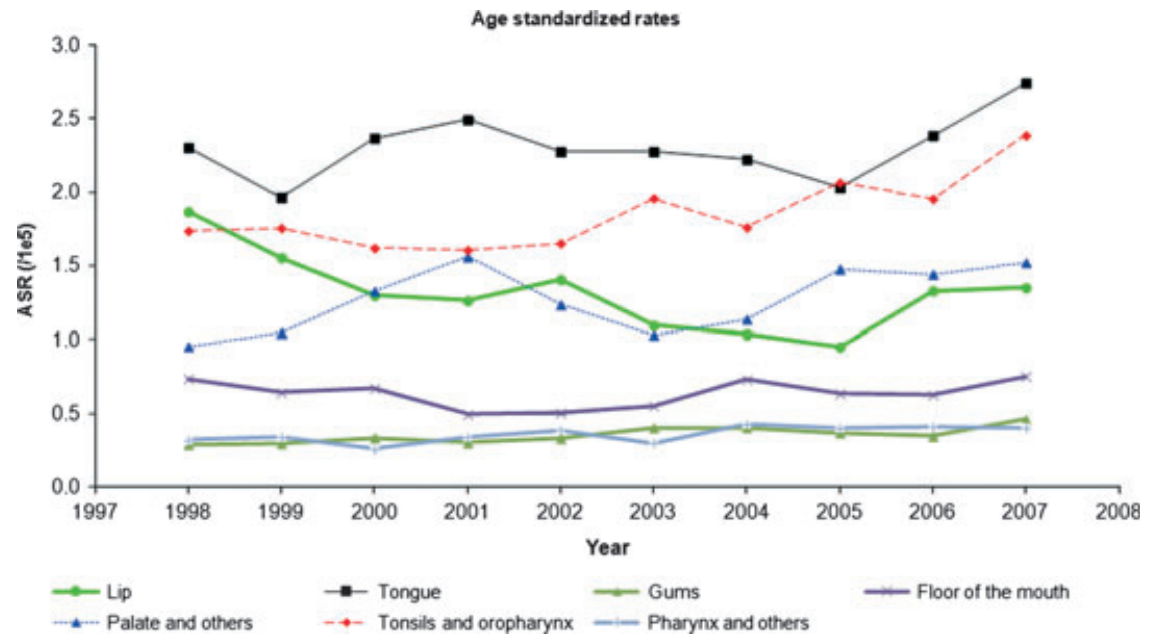

Figure 2 Trends in age-standardized incidence rates in period of 1998-2007 by sites for both sexes.

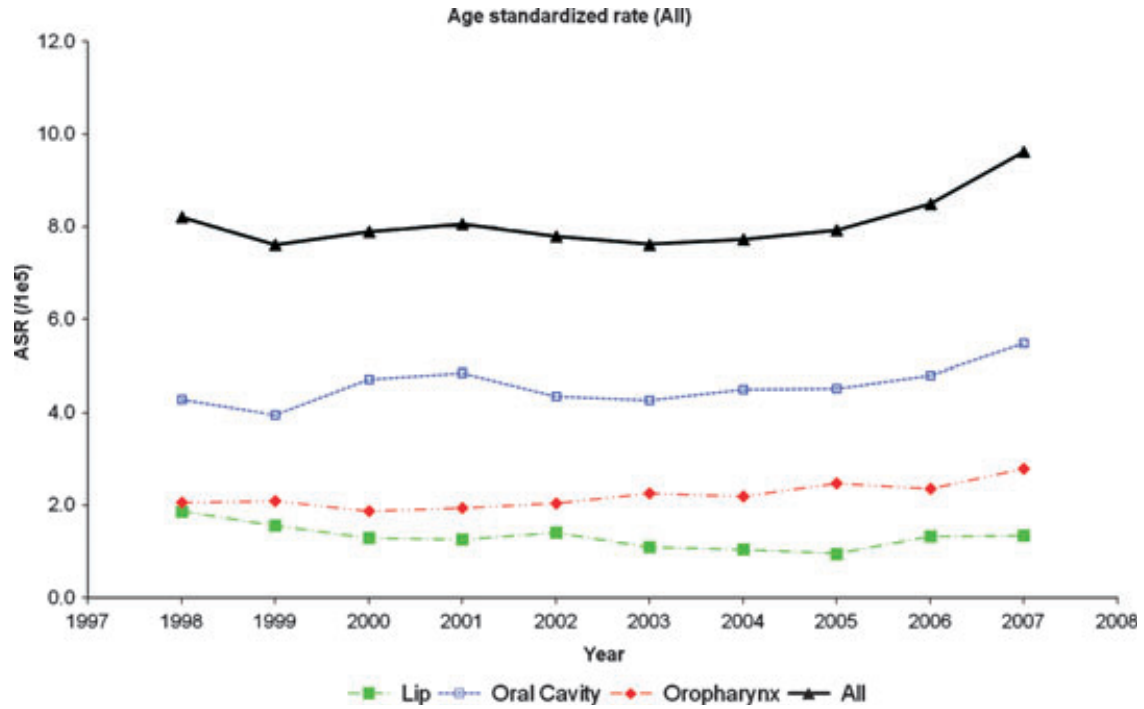

Figure 3 Trends (1998-2007) in age standardized incidence rate for lip, oral, oro-pharyngeal and all cancers for both sexes.

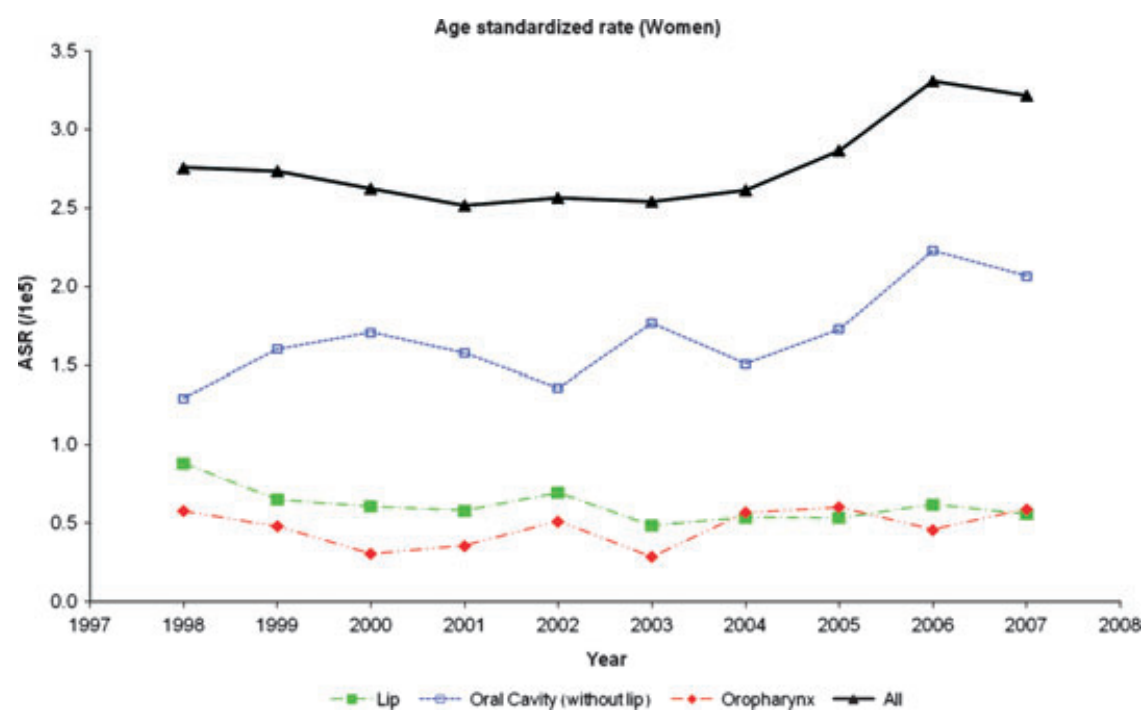

Figure 4 Trends in age standardized incidence rate for lip, oral and oro-pharyngeal cancers for the period from 1998-2007 for women. 


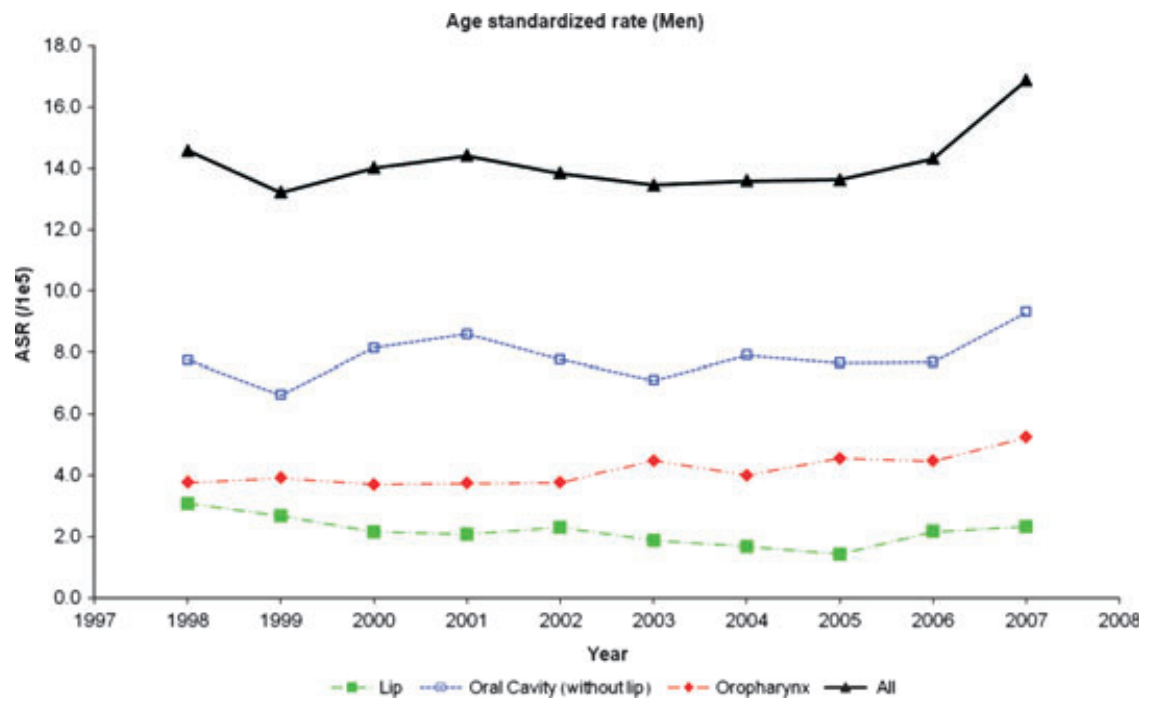

Figure 5 Trends in age standardized incidence rate for lip, oral and oro-pharyngeal cancers for the period from 1998-2007 for males.

oro-pharyngeal cancer. This probably needs further research in Portugal to confirm any associations. Prophylactic vaccination of young people against HPV may eliminate some oral cancers, but it may take years to reverse the trends (29).

Lip cancer was the only cancer that showed a decrease in its incidence rate. This was also observed by Blomberg et al. (30) and highlights the differences in aetiological and epidemiologic characteristics of lip cancer compared with oral and oro-pharyngeal cancers.

The possible poor awareness of the risk factors for oral cancer among the Portuguese population may also contribute to the rising trend in oral and oro-pharyngeal cancers. It is interesting to note that some high-risk countries such as Sri Lanka, who initiated oral cancer screening campaigns some decades ago, have recently, reported a decrease in oral cancer incidence rates (5). It would be necessary to continue to conduct surveillance of oral cancer data in Portugal to see whether this rising trend continues or may show downward trend after 2007 with more recent public health interventions.

In conclusion, our study provides evidence that the incidence of oral and oro-pharyngeal cancers has been rising between 1998 and 2007, in Portugal. This increasing trend was more evident in women for oral cancer and in men for oro-pharyngeal cancer. It is important to follow-up these remarkable changes in the patterns of incidence of oral cancer and to monitor these for the clues they give us to the aetiology, so that the provision of health care for cancer can be better planned. Furthermore, an oral health promotion strategy should be introduced that involves elements of basic education on oral cancer for the Portuguese population, implementation of campaigns on oral cancer awareness, appropriate screening programmes for oral cancer and a will to engage in political measures to reduce tobacco and alcohol use.

\section{References}

1. Warnakulasuriya S. Global epidemiology of oral and oropharyngeal cancer. Oral Oncol 2009; 45: 309-16.
2. Ferlay J, Shin HR, Bray F, Forman D, Mathers C, Parkin DM. GLOBOCAN 2008, Cancer Incidence and Mortality Worldwide: IARC CancerBase No. 10. Lyon, France: International Agency for Research on Cancer, 2010.

3. Warnakulasuriya S. Living with oral cancer: epidemiology with particular reference to prevalence and life-style changes that influence survival. Oral Oncol 2010; 46: 407-10.

4. Warnakulasuriya S. Causes of oral cancer - an appraisal of controversies. Br Dent $J$ 2009; 207: 471-5.

5. Ariyawardana A, Warnakulasuriya S. Declining oral cancer rates in Sri Lanka: are we winning the war after being at the top of the cancer league table? Oral Dis 2011; 17: 636-41.

6. Reichart PA, Dietrich T, Khongkhunthian P, Srisuwan S. Decline of oropharyngeal cancer in Chiangmai province, Thailand, between 1988 and 1999. Oral Oncol 2003; 39: 569-73.

7. Karim-Kos HE, de Vries E, Soerjomataram I, Lemmens V, Siesling S, Coebergh JW. Recent trends of cancer in Europe: a combined approach of incidence, survival and mortality for 17 cancer sites since the 1990s. Eur J Cancer 2008; 44: 1345-89.

8. World Health Organization. International classification of the diseases, 10th revision, 2007. Available at:http://apps.who.int/ classifications/icd10/ (accessed on 9 January, 2012).

9. Boyle P, Parkin DM. Cancer registration: principles and methods. IARC Sci Publ 1991; 95: 126-38.

10. Kim HJ, Fay MP, Feuer EJ, Midthune DN. Permutation tests for joinpoint regression with applications to cancer rates. Stat Med 2000; 19: 335-51.

11. Moller H. Changing incidence of cancer of the tongue, oral cavity, and pharynx in Denmark. J Oral Pathol Med 1989; 18: 224-9.

12. Macfarlane GJ, Boyle P, Evstifeeva TV, Robertson C, Scully C. Rising trends of oral cancer mortality among males worldwide: the return of an old public health problem. Cancer Causes Control 1994; 5: 259-65.

13. Conway DI, Stockton DL, Warnakulasuriya KA, Ogden G, Macpherson LM. Incidence of oral and oropharyngeal cancer in United Kingdom (1990-1999) - recent trends and regional variation. Oral Oncol 2006; 42: 586-92.

14. La Vecchia C, Tavani A, Franceschi S, Levi F, Corrao G, Negri E. Epidemiology and prevention of oral cancer. Oral Oncol 1997; 33: 302-12.

15. Ligier K, Belot A, Launoy G, et al. Descriptive epidemiology of upper aerodigestive tract cancers in France: incidence 
over 1980-2005 and projection to 2010. Oral Oncol 2011; 47: 302-7.

16. Braakhuis BJ, Visser O, Leemans CR. Oral and oropharyngeal cancer in The Netherlands between 1989 and 2006: increasing incidence, but not in young adults. Oral Oncol 2009; 45: e85-9.

17. Ligier K, Belot A, Launoy G, Velten M, Delafosse P, Guizard AV. Epidemiology of oral cavity cancers in France. Rev Stomatol Chir Maxillofac 2011; 112: 164-71.

18. World Health Organization. Global status report on alcohol and health. WHO Press, Geneva, 2011. pp. 273-7. Available at: http://www.who.int/substance_abuse/ publications/global_ alcohol_report/ (accessed on 9 January, 2012).

19. Mello M, Barrias J, Breda J. Álcool e Problemas Ligados ao Álcool em Portugal. Lisboa: DGS, 2001; 27-34.

20. Wong YK, Tsai WC, Lin JC, et al. Socio-demographic factors in the prognosis of oral cancer patients. Oral Oncol 2006; 42: 893-906.

21. Conway DI, Petticrew M, Marlborough H, Berthiller J, Hashibe M, Macpherson LM. Socioeconomic inequalities and oral cancer risk: a systematic review and meta-analysis of case-control studies. Int J Cancer 2008; 122: 2811-9.

22. Llewellyn CD, Johnson NW, Warnakulasuriya KA. Risk factors for squamous cell carcinoma of the oral cavity in young people-a comprehensive literature review. Oral Oncol 2001; 37: 401-18.

23. Shiboski $\mathrm{CH}$, Schmidt BL, Jordan RC. Tongue and tonsil carcinoma: increasing trends in the U.S. population ages 20 44 years. Cancer 2005; 103: 1843-9.

24. Junor EJ, Kerr GR, Brewster DH. Oropharyngeal cancer. Fastest increasing cancer in Scotland, especially in men. BMJ 2010; 340: c2512.

25. Hakulinen T, Tryggvadóttir L, Gislum M, et al. Trends in the survival of patients diagnosed with cancers of the lip, oral cavity, and pharynx in the Nordic countries 1964-2003 followed up to the end of 2006. Acta Oncol 2010; 49: 561-77.

26. Chaturvedi AK, Engels EA, Anderson WF, Gillison ML. Incidence trends for human papillomavirus-related and unrelated oral squamous cell carcinomas in the United States. J Clin Oncol 2008; 26: 612-9.

27. Auluck A, Hislop G, Bajdik C, Poh C, Zhang L, Rosin M. Trends in oropharyngeal and oral cavity cancer incidence of human papillomavirus (HPV)-related and HPV-unrelated sites in a multicultural population: the British Columbia experience. Cancer 2010; 116: 2635-44.

28. Chaturvedi AK, Engels EA, Pfeiffer RM, et al. Human papillomavirus and rising oropharyngeal cancer incidence in the United States. J Clin Oncol 2011; 29: 4294-301.

29. Syrjanen S, Lodi G, von Bultzingslowen I, et al. Human papillomavirus in oral carcinoma and oral potentially malignant disorders: a systematic review. Oral Dis 2011; 17 (Suppl. 1)58-72.

30. Blomberg M, Nielsen A, Munk C, Kjaer SK. Trends in head and neck cancer incidence in Denmark, 1978-2007: focus on human papillomavirus associated sites. Int J Cancer 2011; 129: 733-41.

\section{Acknowledgements}

We would like to thank to the Cancer Registries of Portugal (RORENO, RORCentro and ROR-Sul) for all support to providing of Portuguese available cancer data.

\section{Conflict of interest}

There are no potential conflicts of interest. 